MATEC Web of Conferences 34, 02011 (2015)

DOI: $10.1051 /$ matecconf/ 20153402011

(C) Owned by the authors, published by EDP Sciences, 2015

\title{
The design of brake fatigue testing system
}

\author{
Xiaoya Huang, Hu Zhang, Wei Li \\ Mechanical and Vehicle Engineering School, Beijing Institute of Technology, Beijing, 100081, China
}

\begin{abstract}
Brake is used to reduce the operating speed of the machinery equipment or to make it stop. It is essential for vehicles, climbing machines and many fixed equipment in their safety work. Brake tester is an experimental apparatus to measure and analyse the braking performance. Based on the PLC technology and for the purpose of testing brake shoe friction material's life, this paper designed a virtual brake test platform. In it, inverter were used to control the motor, so that it can load automatically and ensure brake drum constant speed output; what is more, closed loop control system were used to control the brake shoe, so that the cylinder pressure keeps stable in the process of dynamic braking.
\end{abstract}

\section{Introduction}

With the rapidly development of national economy and society, China's highway construction and transportation has made great progress, road mileage is rising year by year. All along, the road transportation industry plays an important role in promoting the development of national economy [1]. In 2009, the logistics industry was identified as one of the top ten revitalization industries vigorously to guide by the state council. As an important part of it, motor transport would attract more attention, and more pressure would be brought to transportation safety at the same time.

As brake is an important part of vehicle, which is crucial to the safety device, the qualified quality and excellent performance of it is a significant guarantee for safety [2-3]. However, the brake especially the drum brake is prone to crack, and even occur the phenomenon of rupture. Therefore, the higher requirements in the safety driving for vehicle braking performance have been put forward.

\section{Brake tester structure}

The friction pair is the main reason for the variation of brake torque, so its measurement turns to be the principal means to judge brake torque. According to the requirements of brake tester performance, in this paper, the prime test scheme and the each step of it were designed to guarantee the accuracy of motor testing torque output.

The system can be divided into three parts: the brake tester structure module, the testing and the control module. The brake tester structure module was the basis to go on the study of brake performance, AC variable frequency speed regulation system were used to produce kinetic energy, drag brake drum, and simulate braking

\footnotetext{
a Corresponding author: author@e-mail.org
}

process. Based on the structure module of brake tester, testing and control module were used to complete the brake performance testing and automation control, data collection, display, processing and preservation, which formed a closed-loop control test system. The structure of brake fatigue tester is shown in Figure 1

K187 motor with the symmetry output axis was adopted (not visible in the Fig 1, connected with the reducer), and the motor was connected with torque sensor directly, which made the motor torque changes measured immediately and real time displayed on the touch screen during the performance testing process.

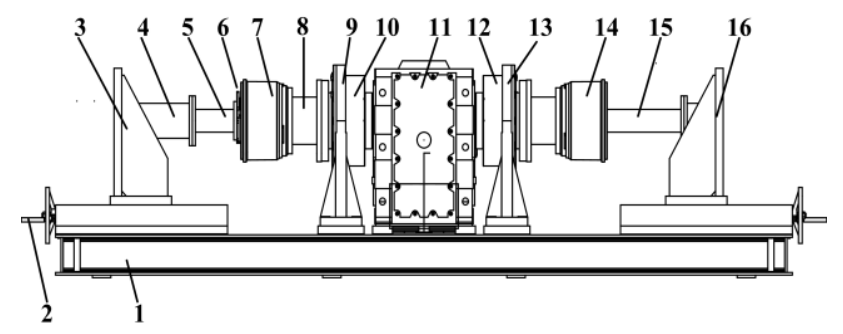

1 body; 2 hand wheel; 3 support; 4 cylinder before the drum brake shoe; 5 Assembly flange before the drum brake shoe; 6 brake shoe; 7 drum brake; 8 output shaft outer flange; 9 bearing support; 10 output shaft inner flange; 11 reducer; 12 bearing sleeve; 13 bearing support; 14 drum brake; 15 Assembly flange after the drum brake shoe; 16 support.

Figure 1. Structure of brake tester.

The design requirements of the brake tester performance:

1). Rotation rate of drum brake is $10 \mathrm{r} / \mathrm{min}$. Brake torque of the brake tester is $40000 \sim 50000 \mathrm{~N}$.m.

2). Measurement parameters: brake torque, rotation speed during the braking process; pedal frequency / braking times, brake chamber pressure. 
3). Liquid-crystal display: brake torque, gas chamber input pressure, braking time, cumulative braking times, stress, speed, torque drop alarm, air pressure alarm, stress drop alarm etc.

4). The system should be able to shut down automatically when the reduction of brake torque or fluctuation exceeds $50 \%$. The system should also be able to shut down automatically when the strain exceeds $100 \%$.

5). It would be better if strain gauge and accelerometer were added to the brake tester and that the numerical reading of each strain gauge and accelerometer could be displayed.

\section{Design of brake drive system}

The way of pneumatic drive was chose for the brake system. With the continuous development of industry mechanization and the improvement of automation, pneumatic force servo has become an important research field in pneumatic technology [4-6]. In this pneumatic device, the operating force was applied through the pneumatic force servo system that controlled by the master computer and can send feedbacks to the master computer through the detection device.

Pneumatic servo system generally consists of controller, electric-pneumatic control components, pneumatic actuator, sensor and interface circuit. The structure diagram of pneumatic servo system can be seen in Figure 2. By adjusting the pneumatic cylinder pressure and the flow valve to obtain the required braking force, then maintain it. In the pneumatic circuit of electrical control, the micro switch controls pneumatic cylinder position and all the directional valves are the solenoid valves. In this paper, the compositions of the speed control loop were air compressor, pneumatic FRL, proportional pressure valve, reversing valve and all the executive elements, which could be seen in Figure 3. The advantages of it are simple structure, low cost and facilitated repair.

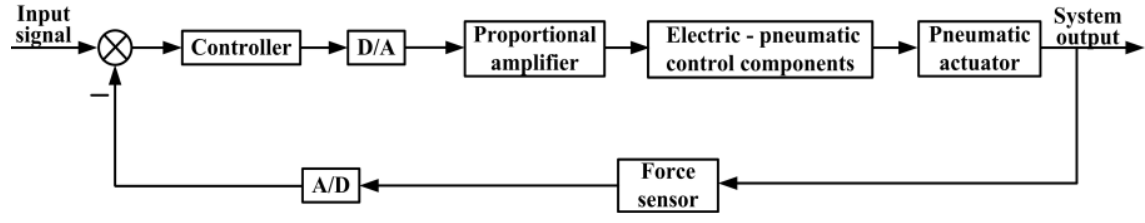

Figure 2. Structure of pneumatic servo system.

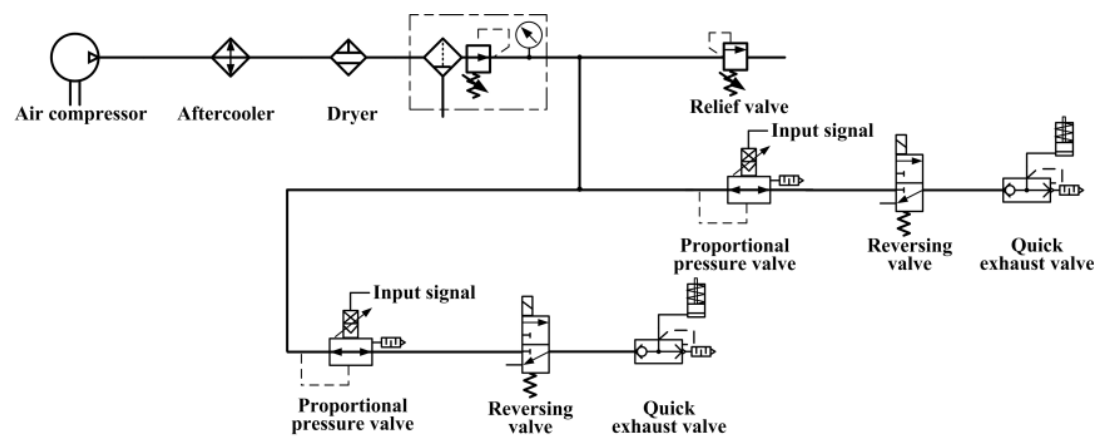

Figure 3. Compositions of the speed control loop.

\section{Design of intelligent test system}

In nowadays, a variety of test technologies have been rapidly developed, and the testing process becomes more efficient, simple and flexible under the control of computer. The test bench is composed of a touch screen (PC), PLC programmable controller, inverter and other parts. The block diagram system as shown in Figure 4.

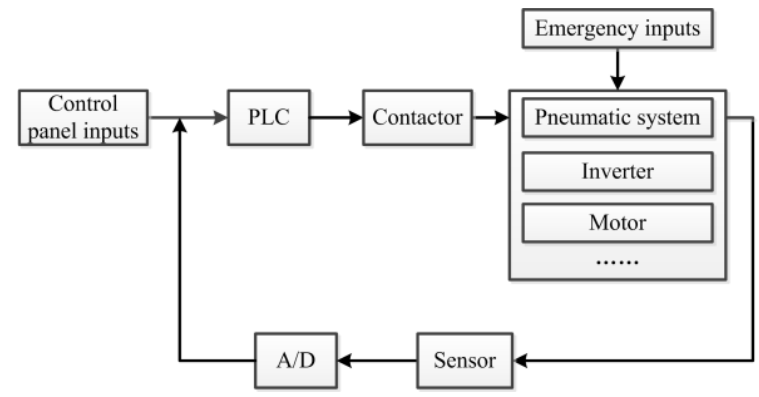

Figure 4. Block diagram system of test bench.
The touch screen monitor the programming of PLC and display variety of parameters. In this design, PLC can control the start and stop of frequency converter and pneumatic system, and communicated with the touch screen through the RS232 communication bus. Besides, the PLC communicated with the frequency converter through the RS485 communication bus. Motor speed was controlled by the frequency converter while the signal's acquisition was controlled by PLC directly. Touch screen can real-time display the measured data and printing curves and charts. To make the test system more safe and reliable, it can also be stopped by the hardware device. In this situation, operator can press the nearest emergency stop button, then the spindle would stop rotating, meanwhile, the whole control circuit was cut off. The testing control system would enter into a electricity failure protection status. It is a double insurance in software and hardware aspects. 


\section{Dynamic loading scheme}

The brake fatigue testing requires constant rotation speed output, according to the driving principle of the motor, the rotation speed is determined by the frequency and the pole pairs. To maintain a constant rotation speed, frequency is the main factor to realise the the aim under the premise of fix pole pairs. Therefore, the inverter was used to achieve this function. The rotation speed expression of the AC asynchronous motor can be shown in Equation 1.

$$
n=\frac{60 f}{p}
$$

$f$ is the frequency of the AC power source $(\mathrm{Hz})$, and $p$ is the number of pole pairs in Asynchronous motor.

The principle of frequency converter is rectified the industry $50 \mathrm{~Hz}$ AC into DC first, then through inverter circuit, turn into the adjustable frequency AC. Protection circuit and control circuit were add to the frequency conversion process in this system.

When starting, frequency converter drive motor revolve from zero to rated rate. while braking, the output of the inverter circuit is zero, but the rotor of the motor and rotating parts of the tester revolve at rated speed. Under the effect of the surplus magnetic field in the stator, $\mathrm{AC}$ motor is in the state of power generation. After inverting circuit and the rectifier circuit, the generated electric energy back into the grid.

\section{Conclusions}

This system integrates computer technology, Automation technology and the advanced information processing technology. In view of the practical application, this paper designed a reasonable testing process, and established a set of information processing system. It is an intelligent fatigue testing system of automobile brake.

\section{Acknowledgements}

This work was financially supported by the National Natural Science Foundation of China (No.51375051).

\section{References}

1. L. Zhao. Research on the Coordinate Development between Logistics Industry and Regional Economy in China. (2013)

2. C. Chengli. The Bench Test of Automobile Brake and the Function Analysis of Friction Material. (2006)

3. Y. Jun, W. Xiufeng, W. Sen. Grain Distribution Technology. J. E 1 (2014)

4. S. Chaoqiang, Z. Ting. Control Theory \& Applications. J. E 27, 11 (2010)

5. X. Ruiping, Y. Guofu, Z. Chengxiao. Hydro mechatronics Engineering. J. E 6 (2004)

6. H. Xiangyu. Adaptive Control Research of Pneumatic Force Control System. (2013) 